UDC 378.147:811.111

DOI: $10.17223 / 24109266 / 10 / 8$

\title{
UP-TO-DATE USAGE OF MOST EFFICIENT TECHNIQUES IN TEACHING ENGLISH
}

\author{
M.A. Kurbakova
}

\begin{abstract}
Mastering a foreign language is always associated with the selection of appropriate techniques. Experienced in teaching English experts, native speakers of the language are advantageous: it resolves the issue of unilateralism of each approach separately, combining these methods together in order to achieve the most effective learning. In contrast to the long time taken in the Russian grammatical explicit method, this experience is based on the implicit approach to the grammar as the basis of linguistic knowledge in any aspect of language. Mastering the language is uniform on four areas: reading, writing, listening, speaking. It allows to master the body language more completely and in a short time.

Keywords: methodological approaches; methods TBE; needs analysis, job scheduling; traditional communicative and humanistic teaching methods; mistakes correction; language aspects.
\end{abstract}

This "archaic" method of teaching is opposed, of course, by the popular and, in the opinion of the overwhelming majority of experts the most effective - the communicative method. It is based on the perception of the language by ear, learning to communicate through the language of communication itself, which is complemented with colorful books with workbooks and a set of disks for listening. However, even this method can not be called universal - without grammatical base it is not surely instills the habit of speaking correctly, and in the absence of language environment such communication is quickly lost.

This brief analysis draws us to the conclusion: the most effective and long-lasting result provides a comprehensive use of the best of all known methods. This complex technique involves the mandatory implementation of grammatical tasks, along with the acquisition of communication skills, listening, writing and comprehensive reading.

In this article, we set the task of considering the advantages of techniques TBE (Teachers of Business English), proposed by the LTTC (London pedagogical college) and supplies a comprehensive program of Longman Teacher Development, which in our opinion, the most reasonable and effective for the student combines the best of the above mentioned methods .

Such training courses are specifically designed to extend the scope of activities, using a compilation of different approaches, styles of training and use of new materials in language learning. The importance of such an integrated approach is undeniable. Working with a student as part of this procedure begins with needs analysis with the use of its various forms, filling the 
menu-approach, when the teacher offers programs that meet the needs and requirements of the student; a personal interview; work-shadowing - the recognition and identification of ways to overcome the obstacles hindering the potential of the individual activated language, including overcoming the language barrier. Finally, this versatile approach provides detailed information about the needs of the student and, if necessary, increased motivation, putting in proper compliance with the training process and the definition of what exactly the potential student needs to do to achieve this goal.

In case of adequate motivation absence this technique suggests using suggestopedia achievements [4] - the construction of a specific educational process with the formation of motivation positive attitude toward it using suggestive techniques.

Meanwhile a teacher proceeds to the job scheduling (lessons planning) with the selected "ingredients" for lessons: authentic materials. This, above all, newspapers, magazines, advertisements, documents, digital recording, radio and TV programs, brochures, reports, internet sticks Kyuizenera the study prepositions of place, the structure of sentences and stress in a word everything that facilitates and diversifies training according to the selected aspect of the language. The teacher selects also headers, tables, tips which will be needed in the course of the lesson. The use of such amounts of visual material provides a visual connection method of teaching, promotes more rapid memorization of grammar and vocabulary.

Generally speaking, TBE methodology offers a combination of the following teaching methods:

1. Communicative method, integrated with some traditional methods using only English-English dictionary. Grammar and vocabulary being studied in the context of implicit approach for grammatical material is mainly characterized by the lack of traffic rules when explaining exercises. This is often a weak point of this method, taken individually.

2. Cultural knowledge teaching method appeals to this aspect as a social and cultural environment of the target language. This "live" method does not aim to master a "lifeless" lexical and grammatical forms, because of $52 \%$ mistakes committed under the influence of the native language, while $44 \%$ - lie within studies. Realizing the importance of this fact, the question of mastering linguistic competence allows properly "dissect" the language of culture under the microscope. This method does not ignore the ace of the basics - grammar and vocabulary, it simply combines them with extralinguistic factors. However, it is naturally one-sided within its limited topic.

3. Humanistic approach is based on the reference to a student as an individual, behaviors of an introvert and extrovert. [3] This approach in educational terms, as a rule, student-centered - a learner is a "center" of the educational process: it shall assess various situations, expresses the opinion concludes, determines their behavior in a particular case, involving in these hu- 
manistic relations: desire complicity, empathy, acceptance of each other, cooperation and joint passion incommunicative and cognitive activity. However, without a thorough working out of grammar rules this method is infringed with fundamentality.

4. Emotion-sense approach involves the creation of interest groups within the class, which contributes to the individual student's motivation and makes it easier to master the necessary knowledge and skills. And this is very important. But it is obvious that it has the same drawbacks like the humanistic approach.

So, to create a robust and thorough method is to connect the existing approaches, integrate them. How is this reflected in practice? The result of applying an integrated approach to language learning are the following activities during the lesson: diverse roleplaying, work with a partner search for comparisons, comparisons of memory and logics, including synonyms, antonyms (find synonyms/opposites), working out of true - incorrect statements (false-true statements), set the "cross out an odd word" (odd word out), search and classify a collective noun for a group of words, the presentation of thoughts, conclusions, mandatory inclusion regional geographic perspective, the practice of making up a dialogue on the basis of the suggested tips; gap-filling, multiple choice, work with the structure of the word - word formation, transformation (paraphrasing) statements, mistake identification and correction. The latter type of work is particularly important because it develops attention to the detail in the student's language.

The most successful techniques of mistake correction at the moment are:

1. Time line. A teacher shows the timeline where the English verbs are marked.

2. Finger method. This is often the method of counting with a finger showing that something has not mentioned yet.

3. Method of facial expressions and gestures associated with the finger method, but here the teacher indicates a fault by other gestures or facial expressions.

4. Writing mistakes on the board. Each student finds his own mistake and corrects it.

5. Freeze technique. Stop and correct the mistake. This technique, however, is not always used, but only to correct frequently repeated fossilized and pronunciation mistakes, as such "stops" of a student slows the development of speaking skills.

6. Work with frequent fossilized mistakes. There is an appointed "expert" - a student who has this problem, should find and correct such mistakes. In most cases these mistakes are associated with the use of the ending -s in the form of 3-person singular, setting articles and the correct Conditionals structure. 
Systematic language training for this technique is designed so that to center a word. The word is studied at the level of its structure - word formation, prefixes and suffixes; the word use, including idioms and metaphors in the lexical and grammatical contexts, i.e. at least a phrase or a text. This multilevel studies main objective is memorizing words. Memorization techniques may also be different:

1) Associative perception (most efficient);

2) Visual perception;

3) The repetition of the word, if necessary, using rhymes;

4) Testing of the words in the current grammar and vocabulary;

5) Tests on memorization;

6) Multiple use in the speech.

The phrase repetition of a word refers not only to multiple mechanical reproduction, but a long process of memorizing; when on the first day a student gets acquainted with a new vocabulary, the 2nd day - the vocabulary is repeated for 10 minutes, on the 7th day - for 5 minutes and finally in a month $-2-4$ minutes. So to effectively memorize the words you are to use as much of the above types of exercises as possible.

Learning vocabulary is in accordance with 4 main aspects of skills development: passive, receptive (reading and listening) and active, productive (speaking and writing). British experts say that the issue of learning English should be represented in the following order: listening - speaking - reading - writing. Note the key points of the approaches to the study of these aspects. In teaching listening skills it is recommended to combine audio listening with reading and act according to the following schedule:

1. Announcement of a theme.

2. Presentation of the pictures to the text.

3. Explanation of how to develop skills on hearing the text.

4. Allocation of unfamiliar words before hearing the whole text.

5. Announcement of the task that needs to be done by listening to the text.

6. Explanation of the fact that on hearing it is not necessary to set the aim to cover all the details but to understand the main idea of the text.

While speaking a trainer should pay attention to the following:

1) Students are to like a topic and age approach is taken into account.

2) Ensuring pair work.

3) Production of various problems.

4) Training of an item or a picture description.

If students do not speak at all, initially they can speak in any language, and then explaining the problem in the language they can understand, and eventually they achieve this goal using already the English language.

With mastering of writing skills students need to be aware of three major objectives: what-why-how - what, how and why they should be spelled out in writing. At the same time it is necessary to distinguish be- 
tween original styles of formal and informal letters and the rules of their spelling. In order to write an essay you should:

1) create a situation described;

2) gather ideas that will be accepted or rejected;

3) consider the plan of writing;

4) immediately set out to draft a letter, check, rewrite, check again.

So authentic techniques and TBE methodology as one of its best options, offers us an integrated approach to language learning. It combines the positive aspects of the available effective approach and therefore is almost perfect. Each of these methods alone is one-sided, and therefore can not be considered perfect, but it should certainly be considered as one of the side to the learning process.

The basis of the success of the authentic techniques and methods of TBE in particular lies in the simultaneous development of all 4 aspects of the language: reading, writing, speaking and listening, which takes into account the achievement of development, above all, communicative method with the implicit approach to the development of grammar, cultural knowledge, suggestopedia as a reflection of humanistic and emotionally-semantic approaches.

As practice shows, at present, the use of the complex of these approaches and methods provides the most efficient absorption of the whole body language for a variety of purposes.

\section{References}

1. Teaching materials TBE LTTC. Cambridge. (2012)

2. Materials of the integrated program Longman Teacher Development. Macmillan. (2009).

3. Razzhivina, E.A., Gushina, N.B.: [Adaptation of the textbook New Blue Print Intermediate to the federal program in the light of the humanistic approach to learning English]. URL: http://referat.guru.ua/referat/16378/

4. Suggestopedia. Educational articles for students. URL: http://www.feshouse.com/catalog/ section/metodika_obucheniya/page/suggestopaedia

Information about the authors:

Kurbakova M.A. - Ph.D., Associate Professor of the "Center for the Study of the English", Moscow Polytechnic University (Moscow, Russia). E-mail: mkurbakova@inbox.ru 